\title{
Consumers Attitude and Behavior Towards Domestic Waste Recycling in Developing Countries: A Case Study
}

\section{Bendak $S^{*}$ and Attili AB}

Department of Industrial Engineering and Engineering Management, University of Sharjah, United Arab Emirates

*Corresponding author: Bendak S, Department of Industrial Engineering and Engineering Management, University of Sharjah, PO Box 27272, Sharjah, United Arab Emirates, Tel: +971-6-5053918; Fax: +971-6-5053963; E-mail: sbendak@sharjah.ac.ae

Received date: March 14, 2017; Accepted date: April 3, 2016; Published date: April 10, 2016

Copyright: $\odot 2017$ Bendak S, et al. This is an open-access article distributed under the terms of the Creative Commons Attribution License, which permits unrestricted use, distribution, and reproduction in any medium, provided the original author and source are credited.

\begin{abstract}
Participation of consumers in any domestic waste recycling program is vital for its success. Many developing countries are starting domestic waste recycling programs but little is known on the attitude or behavior of consumers toward this issue. This presents a hurdle to the success of such programs. This paper addresses consumers' attitude and behavior toward domestic waste recycling in the United Arab Emirates (UAE). A specially tailored questionnaire was randomly distributing to a sample of one thousand consumers in UAE asking them a multitude of questions on their attitude, behavior and practices in relation to domestic waste recycling. Results indicate that only a small percentage of people actually participate in recycling even though they are aware of the deteriorating environmental quality and acknowledging that recycling preserves resources and protects the environment. Results also show that this difference between consumers' attitude and practices might be due to some obstacles including lack of recycling bins and the long distance needed to reach those bins. Finally, some practical solutions to improve consumers' participation in recycling in UAE are given.
\end{abstract}

Keywords: Domestic waste management; Recycling; Consumer's attitude and behavior; Environmental Quality; Environmental protection; United Arab Emirates

\section{Introduction}

Following the industrial revolution, large quantities of waste have been increasingly generated across the globe. The issue of managing this waste has been increasingly gaining attention of both authorities and the general public. Recycling is considered as the most successful strategy to deal with post-purchased waste $[1,2]$.

Recycling as the return of waste materials to the productive system through utilizing them in the manufacturing of goods with the ultimate aim of preserving non-renewable resources [3]. The author stresses that recycling goes beyond reusing a product (such as glass bottles) and involves the return of salvaged materials, such as plastics, to an early manufacturing stage, e.g., melting of plastics. Therefore, recycling helps in reducing usage of raw materials, reducing water and air pollution and reducing the need for waste disposal [4].

In general, consumers' participation in recycling domestic waste is essential in any waste management system. Separation of recyclables by consumers at the source makes the recovery process of recyclable items much easier and more cost effective than separating them at waste collection centers after they get contaminated with water, organic waste, oil, and other types of waste. Therefore, separation of recyclable materials by consumers at the source is essential for any effective recycling effort $[5,6]$.

Positive consumer attitude toward recycling of domestic waste (also known as household waste) is vital $[7,8]$. Without public contribution, recycling waste would not be possible. The authors stressed also that in order to support recycling projects, it is important to understand who recycles, why they recycle and how they recycle [9].
The literature on people's attitude and behavior towards recycling is diverse in terms of tools used and results obtained. For example, public perception, through surveying a sample of households, in Ningbo city (China) of the local environmental quality as well as people's awareness and willingness to make green purchases to improve environmental quality [10]. The authors found that Ningbo residents reported not being pleased with the city's environmental quality and that residents are highly willing to share responsibility of the environment. Of the 2096 respondents to the questionnaire, 64\% said they have heard of the Chinese government environmental program, $70 \%$ were willing to pay to improve environmental quality and $80 \%$ did not mind purchasing environmentally friendly products.

The domestic waste recycling behavior of residents of Tioman Island, Indonesia [1]. The rapid increase in solid waste on the island became a major environmental problem and authorities wanted to encourage recycling as one of the solutions to this problem. The authors investigated recycling behavior among 62 Tioman Island residents through a structured questionnaire of 33 items. The authors found that lack of awareness and negative behavior toward recycling were hindering the recycling process.

In Canada, the domestic waste recycling behaviour of two generations of South Asians in Ontario city using a combination of semi structured surveys and interviews with 341 South Asian Canadians [11]. Significant differences were observed between the two groups. Second generation respondents viewed recycling more favorably, they also indicated higher levels of recycling participation, awareness and willingness to respond to recycling promotion and education literature. The authors also found that source separation of recyclables was not a common waste management practice in first generation respondents' country of origin. The authors added that this lack of past participation in recycling programs might serve as a barrier to recycling behaviour, potentially explaining differences in 
levels of recycling participation between first and second generation South Asians in Ontario.

It is well documented in the literature that municipal solid waste is a lead cause of underground water contamination which, in turn, can lead to a serious toxic risk to human beings and other living orgasms in that area $[12,13]$. Recycling helps in lowering this amount of municipal solid waste directed to landfills. This in turn helps in better management of municipal waste and in minimizing detrimental solid waste effects on groundwater and soil quality $[12,14]$.

The above literature reveals that recycling of domestic waste would not be possible without the contribution of the public. Peoples' attitude is found to be the key to the success of any recycling program. Therefore, it is very important to understand consumer's attitude and behaviour toward recycling programs. People seem to have the awareness and positive attitudes toward the disposal of waste materials [15]. However, positive attitudes do not guarantee participation in waste management programs [16-18]. Therefore, and in order to enhance recycling projects, it is very important to understand who recycles and why and how do they recycle.

The United Arab Emirates, also known as UAE, is one of the six gulf countries located in the southeast end of the Arabian Peninsula, bordering Saudi Arabia to the south and Oman to the east. The country is a federation of seven emirates with a total area of 71023.6 Sq. km. In 2013, the total population of UAE was 9.2 million, with 1.4 million of them being Emirati citizens and the remaining 7.8 million being expatriates [19].

Given the fact that UAE is considered a high-income country, official statistics show that the total amount of waste generated in 2013 was in excess of 27 million tons. This translates to approximately 2.7 kilograms of waste per person per day [19]. No official statistics are available on how this amount is distributed among the different types of waste.

The aim of this paper is to examine consumers' attitude and behaviour towards domestic waste recycling in UAE and to put forward some suggestions to improve participation in recycling. This will ultimately contribute to minimizing waste and preserving the environment knowing that no published articles on consumers' attitude and behaviour within the UAE context, to the knowledge of the authors, exist in this area.

\section{Methodology}

\section{Questionnaire}

It is clear from the published literature that most studies assessing people's attitude and behaviour towards recycling utilized structured questionnaires. In the current study, a questionnaire of four sections was developed and distributed. The first section enquired about demographic data of respondents as follows:

Age $(<20,21-30,31-40,41-50,>51)$

Gender

Nationality (UAE, Arab, Asian, North American/European, other)

Highest level of education achieved (high school or lower, diploma, bachelor, masters or higher)

Marital status (single, married, divorced, other)
For the nationality question, since more than $95 \%$ of residents are either UAE citizens or come from Arab countries (excluding UAE), South, East and South-East Asia (mainly India, Pakistan, Bangladesh, Sri Lanka, Nepal, Indonesia and the Philippines; hereafter referred to as Asian) or European/North American countries [19], respondents were asked to choose one of the five mentioned options.

The second section of the questionnaire asked respondents to choose, on a 5-point Likert scale ranging from strongly agree (given a weight of 5) to strongly disagree (given a weight of 1), the best option that corresponds to their awareness, attitude and/or practices relating to 13 statements on recycling and the environment. These statements were as follows:

1. I think recycling is important

2. Recycling helps prevent wasteful behaviour

3. Recycling makes the world a better place

4. Recycling is a waste of time

5. Each consumer can contribute to solving the waste problem

6. Recycling benefits are worth my time and effort

7. Governments should force producers to use recyclable materials in their packaging

8. It is my personal responsibility to help in the recycling effort

9. Recycling is a great help to environmental protection

10. It is useless to recycle while only few people are doing that

11. I'm concerned about the environment

12. I'm concerned about global warming

13. Environmental quality is deteriorating

The third section asked respondents to estimate the percentage of five different consumable materials they recycle, namely plastics, aluminum, glass, metals and textiles. Respondents could choose among five possible responses as follows: $\leq 10 \%$ (weight: 1 ), $11-35 \%$ (weight: 2), 36-65\% (weight: 3), 66-89\% (weight: 4) and $\geq 90 \%$ (weight: 5). The one to five weight given is for statistical analysis purposes.

The fourth and last section of the questionnaire consisted of six questions given in Table 1.

\begin{tabular}{|l|l|}
\hline Questions & Answers \\
\hline $\begin{array}{l}\text { How do you receive information } \\
\text { about recycling? (tick all } \\
\text { applicable) }\end{array}$ & $\begin{array}{l}\text { Leaflets/posters } \\
\text { General perception/knowledge } \\
\text { Newspaper articles } \\
\text { Neighbors } \\
\text { Internet } \\
\text { Radio/television } \\
\text { School/university lessons }\end{array}$ \\
\hline $\begin{array}{l}\text { How recent have you received } \\
\text { information about recycling? }\end{array}$ & $\begin{array}{l}\text { In the last month } \\
\text { In the last } 6 \text { months } \\
\text { In the last year } \\
\text { In the last 2 years } \\
\text { None that you know of }\end{array}$ \\
\hline $\begin{array}{l}\text { Why do you recycle? (tick all } \\
\text { applicable) }\end{array}$ & $\begin{array}{l}\text { Recycling saves energy } \\
\text { Recycling reduces landfills } \\
\text { Recycling preserves resources and protects } \\
\text { the environment }\end{array}$ \\
\hline
\end{tabular}




\begin{tabular}{|l|l|}
\hline & $\begin{array}{l}\text { Recycling is good for the economy } \\
\text { Others }\end{array}$ \\
\hline $\begin{array}{l}\text { How convenient do you find } \\
\text { recycling? }\end{array}$ & $\begin{array}{l}\text { Very Convenient } \\
\text { Convenient } \\
\text { Neutral } \\
\text { Slightly inconvenient } \\
\text { Not convenient at all (long distance to } \\
\text { recycling bins) }\end{array}$ \\
\hline $\begin{array}{l}\text { Do you think there are enough } \\
\text { paper recycling bins? }\end{array}$ & $\begin{array}{l}\text { Yes. } \\
\text { No. } \\
\text { I don't know/not applicable. }\end{array}$ \\
\hline $\begin{array}{l}\text { What would encourage your } \\
\text { participation in recycling? (tick } \\
\text { all applicable) }\end{array}$ & $\begin{array}{l}\text { Short walking distance to recycling bins } \\
\text { More recycling bins } \\
\text { Mass media education and promotion } \\
\text { Additional benefit redeeming from recycling. } \\
\text { More frequent waste collection. } \\
\text { Clear recycling guidelines. } \\
\text { Introduce laws and regulations that enforce } \\
\text { and regulate recycling. }\end{array}$ \\
\hline
\end{tabular}

Table 1: Questions of section 4 of the questionnaire.

All questionnaire contents were based on previously developed and validated surveys. Specifically, statements of the 2 nd section of the questionnaire except the last three, section 3 and questions 3 and 4 of the 4 th section were based on similar items in a survey conducted by Latif and Omar [1]. The last three statements of the 2nd section was based on the work of Nnorom [2]. Questions 1 and 2 of the 4th section are based on questions developed by Evison and Read [20]. Finally, the last two questions of the 4 th section were based on a survey on recycling that was published online on Survey Monkey website (www.surveymonkey.com). It should also be noted that many questionnaire items were altered to suit the UAE context.
The targeted sample size in this study was 1000 so data collection stopped when the number of responses reached 1000. However, 11 questionnaire responses had to be discarded due to invalid or missing responses. Therefore, data from 989 valid questionnaires were evaluated. This is deemed enough when compared to similar studies in other countries like 1000 in Nigeria by Nnorom et al. [2] and in England by Evison and Read [20]. The survey was distributed randomly to potential respondents in English and Arabic and the respondent had the choice of answering the questions in either language if they chose to participate.

Data collection took place between March and June 2016. The questionnaire was distributed randomly to potential respondents across all emirates of the UAE on a face to face basis. After giving a short briefing on the study, people were asked if they were willing to participate. Participation rate was more than $70 \%$ while no information was collected on non-respondents.

Descriptive statistics were used first to explore the responses. Then for gender, a t-test was done to check its effects on output variables explored in the questionnaire. As normality of all other demographic factors in the survey (i.e., age, nationality, education and marital status) could not be assumed due to the limited number of response levels (between three and five), a non-parametric test, namely KruskalWallis one-way analysis of variance, was done using SPSS version 22. Significance level adopted in this study is $\alpha=0.05$.

\section{Results}

Demographic characteristics of those who responded to the survey are given in Table 2. As can be seen in this table, respondents represented a wide variety of people in terms of all demographic characteristics, i.e. age, gender, nationality, education level and marital status. Responses to the 2 nd section of the questionnaire are given in Table 3.

\begin{tabular}{|c|c|c|c|c|c|}
\hline Age & $<20: 7.8 \%$ & 20-29: $2.8 \%$ & $30-39: 27.3 \%$ & $40-49: 6.9 \%$ & $>50: 12.8 \%$ \\
\hline Gender & Male: $44 \%$ & Female: $56 \%$ & & & \\
\hline Nationality & UAE: $25.3 \%$ & Other Arab: $49.5 \%$ & Nth Amer./Europ: $4.2 \%$ & Asian: $14.8 \%$ & Other: $6.3 \%$ \\
\hline Education level & High school or lower: $21.5 \%$ & Diploma: $10.7 \%$ & BSc: $61 \%$ & MSc or higher: $6.8 \%$ & \\
\hline Marital Status & Single: $32.3 \%$ & Married: $66.6 \%$ & Divorced: $0.8 \%$ & Other: $0.3 \%$ & \\
\hline
\end{tabular}

Table 2: Demographic characteristics of questionnaire respondents.

\begin{tabular}{|l|l|l|l|l|l|}
\hline Questions on recycling & Strongly agree & Agree & $\begin{array}{l}\text { Neither agree nor } \\
\text { disagree }\end{array}$ & Disagree & $\begin{array}{l}\text { Strongly } \\
\text { disagree }\end{array}$ \\
\hline 1) I think recycling is important & $67 \%$ & $31 \%$ & $2 \%$ & $0 \%$ & $0 \%$ \\
\hline 2) Recycling helps prevent wasteful behaviour & $48 \%$ & $43 \%$ & $8 \%$ & $1 \%$ & $0 \%$ \\
\hline 3) Recycling makes the world a better place & $54 \%$ & $42 \%$ & $3 \%$ & $1 \%$ & $0 \%$ \\
\hline 4) Recycling is a waste of time & $2 \%$ & $6 \%$ & $7 \%$ & $39 \%$ & $46 \%$ \\
\hline
\end{tabular}




\begin{tabular}{|c|c|c|c|c|c|}
\hline $\begin{array}{l}\text { 5) Each consumer can contribute to solving the waste } \\
\text { problem }\end{array}$ & $53 \%$ & $39 \%$ & $7 \%$ & $1 \%$ & $0 \%$ \\
\hline 6) Recycling benefits are worth my time and effort & $38 \%$ & $47 \%$ & $11 \%$ & $4 \%$ & $1 \%$ \\
\hline $\begin{array}{l}\text { 7) Governments should force producers to use recyclable } \\
\text { materials in their packaging }\end{array}$ & $42 \%$ & $41 \%$ & $14 \%$ & $2 \%$ & $1 \%$ \\
\hline 8) It is my personal responsibility to help in the recycling effort & $46 \%$ & $43 \%$ & $9 \%$ & $1 \%$ & $1 \%$ \\
\hline 9) Recycling is a great help to environmental protection & $57 \%$ & $34 \%$ & $8 \%$ & $1 \%$ & $0 \%$ \\
\hline $\begin{array}{l}\text { 10) It is useless to recycle while only few people are doing } \\
\text { that }\end{array}$ & $4 \%$ & $16 \%$ & $10 \%$ & $38 \%$ & $32 \%$ \\
\hline 11) I'm concerned about the environment & $38 \%$ & $48 \%$ & $14 \%$ & $1 \%$ & $0 \%$ \\
\hline 12) I'm concerned about global warming & $33 \%$ & $37 \%$ & $27 \%$ & $2 \%$ & $1 \%$ \\
\hline 13) Environmental quality is deteriorating & $34 \%$ & $41 \%$ & $23 \%$ & $2 \%$ & $0 \%$ \\
\hline
\end{tabular}

Table 3: General perception towards recycling.

Table 3 shows that $98 \%$ of respondents either strongly agree or agree that recycling is important, $91 \%$ strongly agree or agree that recycling helps prevent wasteful behaviour and $96 \%$ strongly agree or agree that recycling makes the world a better place. Interestingly, no one among the 989 respondents indicated their strong disagreement with the first three statements. When asked if recycling is a waste of time, $46 \%$ strongly disagreed and $39 \%$ disagreed while $6 \%$ agreed and only $2 \%$ strongly agreed.

Out of the 989 respondents, $92 \%$ strongly agreed or agreed that each consumer can contribute to solving the waste problem. Moreover, $85 \%$ indicated that they strongly agree or agree that recycling benefits are worth the time and effort spent while $83 \%$ strongly agreed or agreed that governments should force producers to use recyclable materials in their packaging. Also, $89 \%$ said that it is their personal responsibility to help in the recycling effort while $91 \%$ indicated their strong agreement or agreement that recycling is a great help to environmental protection. For statement $10,70 \%$ indicated their strong disagreement or agreement that it is useless to recycle while only few people are doing that.

Statements 11 and 12 revealed interesting outcome. While $86 \%$ of respondents indicated that they care about the environment, only $70 \%$ indicated caring about global warming. Finally, $75 \%$ of all respondents indicated that they agree or strongly agree with the statement that environmental quality is deteriorating.

As for the 3rd section of the questionnaire, reported percentages of materials recycled by respondents are given in Table 4 .

\begin{tabular}{|c|c|c|c|c|c|}
\hline & $\begin{array}{l}\leq \\
10 \%(1)\end{array}$ & $11 \%-35 \%(2)$ & $36 \%-65 \%(3)$ & $66 \%-89 \%(4)$ & $\begin{array}{l}\geq \\
\text { (5) }\end{array}$ \\
\hline Plastics & $73 \%$ & $14 \%$ & $7 \%$ & $4 \%$ & $1 \%$ \\
\hline Aluminum & $89 \%$ & $7 \%$ & $2 \%$ & $1 \%$ & $1 \%$ \\
\hline Glass & $83 \%$ & $11 \%$ & $4 \%$ & $1 \%$ & $1 \%$ \\
\hline Metals & $89 \%$ & $6 \%$ & $3 \%$ & $1 \%$ & $1 \%$ \\
\hline Textiles & $52 \%$ & $12 \%$ & $13 \%$ & $6 \%$ & $17 \%$ \\
\hline
\end{tabular}

Table 4: Percentage of materials recycled.
Based on the responses, it is very clear that very little aluminum, glass and metals is being recycled with $83 \%$ or more of respondents reporting recycling less than $10 \%$ of what they produce. Recycling of plastics turned to be higher with $73 \%$ reported recycling less than $10 \%$. The case is different when it comes to textiles where $52 \%$ reported recycling less than $10 \%$ and $17 \%$ reported recycling more than $90 \%$ with the remaining $31 \%$ lying in between.

The first three questions of section 4 were designed in a way that allows respondents to choose one or more applicable answers. Responses (in percentage terms) to the first question of this section on ways where respondents are getting their information about recycling from are presented in Figure 1. As can be seen in the figure, the internet is reported to be the leading source of information on recycling according to $73 \%$ of respondents. The internet is followed by other means like radio/TV channels (24\%), printed materials like posters and leaflets (20\%) and newspaper articles (19\%).

Responses to the second question on the reasons for recycling are given in Figure 2. As can be seen in that figure, $65 \%$ of respondents indicated the reason as to protect the environment followed by being good for the economy (35\%) and to reduce landfills (32\%).

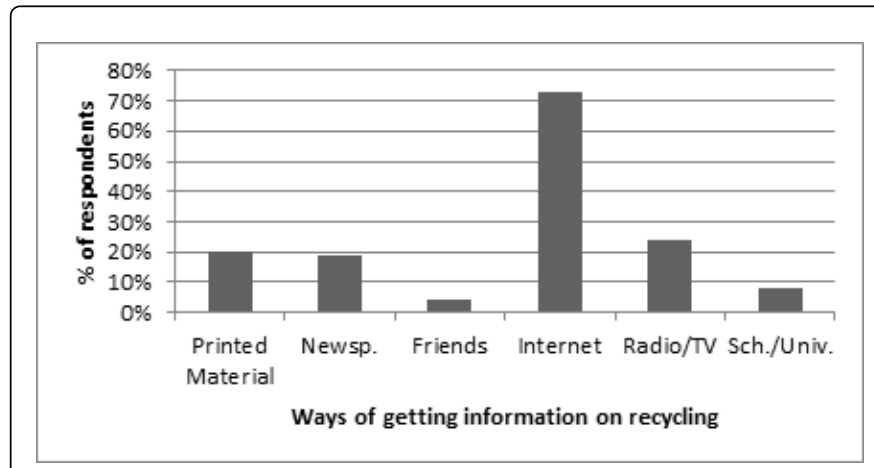

Figure 1: Responses to "How do you receive information about recycling?" question. 
Page 5 of 8

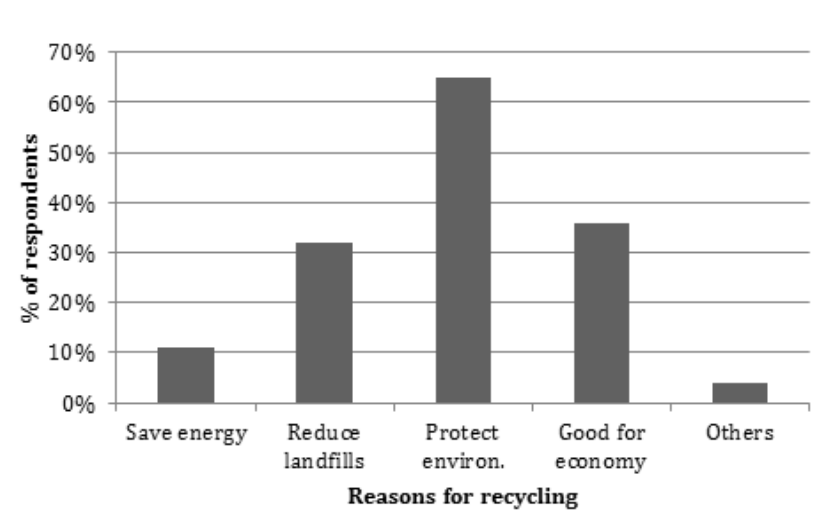

Figure 2: Responses to "Why do you recycle?" question.

Responses to the third question on recycling encouraging factors are given in Figure 3. Responses of this question indicate that more recycling bins $(48 \%)$, short walking distance to recycling bins (42\%), more redeemed benefits (30\%), introducing enforcing laws (28\%) and more education and promotion on recycling $(27 \%)$ would encourage recycling. More frequent collection (21\%) and clearer recycling guidelines (18\%) were the least reported encouraging factors for recycling.

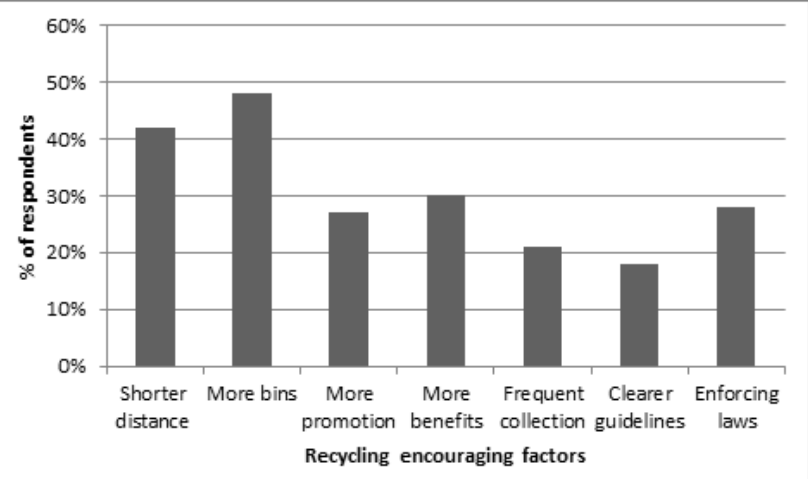

Figure 3: Responses to "What would encourage your participation in recycling?" question.

Responses to the last three questions of section 4 on consumer attitude are given in Table 5. As can be seen in that table, $26 \%$ of respondents indicated not receiving any messages on the importance of recycling at all while many others reported not getting such messages on a regular basis. Also, almost two thirds of the respondents reported not finding recycling to be convenient for them and think that there are not enough paper recycling bins.

\begin{tabular}{|l|l|l|}
\hline Question & Response & Percentage \\
\hline \multirow{2}{*}{ How recent have you received } & In the last month & $16 \%$ \\
\cline { 2 - 3 } & In the last 6 months & $27 \%$ \\
\hline
\end{tabular}

\begin{tabular}{|c|c|c|}
\hline \multirow[t]{3}{*}{ information about recycling? } & In the last year & $20 \%$ \\
\hline & In the last 2 years & $11 \%$ \\
\hline & $\begin{array}{l}\text { None that you know } \\
\text { of }\end{array}$ & $26 \%$ \\
\hline \multirow{5}{*}{$\begin{array}{l}\text { How convenient do you find } \\
\text { recycling? }\end{array}$} & Very Convenient & $11 \%$ \\
\hline & Convenient & $15 \%$ \\
\hline & Neutral & $11 \%$ \\
\hline & Slightly inconvenient & $30 \%$ \\
\hline & Not convenient at all & $33 \%$ \\
\hline \multirow{3}{*}{$\begin{array}{l}\text { Do you think there are enough paper } \\
\text { recycling bins? }\end{array}$} & Yes & $20 \%$ \\
\hline & No & $65 \%$ \\
\hline & I don't know/NA & $15 \%$ \\
\hline
\end{tabular}

Table 5: General recycling questions.

As mentioned earlier, an unpaired t-test was done to test the effects of gender on output variables and Kruskal-Wallis one-way analysis of variance was done to test the effects of other demographic characteristics. Significant results due to gender differences are given in Table 6. Although all questionnaire items listed in Table 6 indicate a statistically significant difference between males and females, these differences were negligible in real-life terms, except for recycling textiles. Females have indicated recycling textiles more than males and this difference was both statistically significant and visible $(2.5 \mathrm{vs}$. 1.989).

\begin{tabular}{|l|l|l|l|}
\hline \multirow{2}{*}{ Question } & \multicolumn{2}{|l|}{ Mean } & p-value \\
\cline { 2 - 3 } & Male & Female & \\
\hline Statement 9 & 4.43 & 4.527 & 0.04 \\
\hline Plastics & 1.279 & 1.451 & 0.002 \\
\hline Aluminum & 1.066 & 1.159 & 0.004 \\
\hline Glass & 1.143 & 1.265 & 0.003 \\
\hline Metals & 1.111 & 1.199 & 0.027 \\
\hline Textiles & 1.989 & 2.5 & 0 \\
\hline How Convenient & 3.621 & 3.347 & 0.004 \\
\hline
\end{tabular}

Table 6: Significant effects of gender on output variables.

Significant results due to differences in age are given in Table 7. Although all questionnaire items listed in this table indicate statistically significant differences among the different age groups, these differences are negligible in real-life terms. 
Citation: Bendak S, Attili AB (2017) Consumers Attitude and Behavior Towards Domestic Waste Recycling in Developing Countries: A Case Study. Adv Recycling Waste Manag 2: 124. doi:10.4172/2475-7675.1000124

Page 6 of 8

\begin{tabular}{|l|l|l|l|l|l|l|l|}
\hline \multirow{2}{*}{ Question } & \multicolumn{2}{l}{ Mean } & \multicolumn{4}{l|}{ p-value } \\
\cline { 2 - 8 } & $<20$ & $20-29$ & $30-39$ & $40-49$ & $50-59$ & $>60$ \\
\hline Statement 2 & 4.412 & 4.244 & 4.445 & 4.477 & 4.421 & 4.304 & 0.004 \\
\hline Statement 3 & 4.265 & 4.446 & 4.555 & 4.548 & 4.491 & 4.13 & 0.004 \\
\hline Statement 5 & 4.471 & 4.539 & 4.49 & 4.503 & 4.395 & 4.043 & 0.01 \\
\hline Statement 7 & 4.235 & 4.279 & 4.249 & 4.29 & 4.018 & 3.913 & 0.02 \\
\hline Statement 8 & 4.265 & 4.167 & 4.351 & 4.465 & 4.491 & 4.13 & 0 \\
\hline Statement 9 & 4.618 & 4.496 & 4.465 & 4.49 & 4.526 & 4.043 & 0.036 \\
\hline Statement 10 & 0.824 & 0.915 & 0.735 & 0.639 & 0.684 & 0.739 & 0.002 \\
\hline Statement 13 & 4.176 & 3.903 & 4.065 & 4.219 & 4.149 & 3.739 & 0.001 \\
\hline Metals & 1.118 & 1.267 & 1.102 & 1.116 & 1.114 & 1.13 & 0.018 \\
\hline Textiles & 2.529 & 2.473 & 2.02 & 2.2 & 2.351 & 2.261 & 0.031 \\
\hline How convenient & 3.5 & 3.279 & 3.4 & 3.484 & 4.035 & 3.478 & 0 \\
\hline Paper recycling bins & 1.882 & 1.93 & 1.918 & 1.903 & 2.149 & 2 & 0.01 \\
\hline Recent information & 3.324 & 2.761 & 3.069 & 2.942 & 3.535 & 3.174 & 0 \\
\hline
\end{tabular}

Table 7: Significant age effects on output variables.

Significant results due to differences in nationality are given in Table 8. Although all questionnaire items listed in this table indicated statistically significant differences among the different nationality groups, these differences are negligible in real-life terms. Nevertheless, it can be noted, however, that North American/European respondents recorded greater statement agreement rates than all other groups in all six statements. This might reflect the greater awareness about environmental issues among this group than other groups of respondents. Also, UAE nationals reported a notably greater textile recycling rate than other groups followed by Arab and North American/European respondents.

\begin{tabular}{|l|l|l|l|l|l|l|}
\hline \multirow{2}{*}{ Question } & \multicolumn{3}{|l|}{ Mean } & \multicolumn{5}{|l|}{} & $\begin{array}{l}\text { p- } \\
\text { value }\end{array}$ \\
\cline { 2 - 7 } & UAE & Arab & $\begin{array}{l}\text { Nth America/ } \\
\text { Europe }\end{array}$ & Asian & Other & \\
\hline Statement 1 & 4.583 & 4.642 & 4.667 & 4.697 & 4.811 & 0.039 \\
\hline Statement 2 & 4.319 & 4.351 & 4.567 & 4.503 & 4.396 & 0.044 \\
\hline Statement 5 & 4.505 & 4.449 & 4.833 & 4.524 & 4.302 & 0.004 \\
\hline Statement 7 & 4.31 & 4.234 & 4.433 & 4.124 & 3.962 & 0.015 \\
\hline Statement 11 & 4.134 & 4.239 & 4.533 & 4.317 & 4.151 & 0.012 \\
\hline Statement 13 & 3.991 & 4.062 & 4.4 & 4.103 & 3.868 & 0.04 \\
\hline
\end{tabular}

\begin{tabular}{|l|l|l|l|l|l|l|}
\hline Plastic & 1.398 & 1.416 & 1.767 & 1.172 & 1.283 & 0.001 \\
\hline Glass & 1.222 & 1.247 & 1.5 & 1.11 & 1 & 0 \\
\hline Textiles & 2.69 & 2.325 & 2.2 & 1.752 & 1.585 & 0 \\
\hline $\begin{array}{l}\text { How } \\
\text { Convenient }\end{array}$ & 2.898 & 3.623 & 3.533 & 3.641 & 4.208 & 0 \\
\hline
\end{tabular}

Table 8: Significant nationality effects on output variables.

Significant results due to differences in education level and marital status are given in Tables 9 and Table 10 respectively. Although all questionnaire items listed in these two tables indicate statistically significant differences due to education level and marital status, these differences were negligible in real-life terms

\begin{tabular}{|l|l|l|l|l|l|}
\hline \multirow{2}{*}{ Question } & \multicolumn{4}{|l|}{ Mean } & p-value \\
\cline { 2 - 5 } & $\begin{array}{l}\text { High school } \\
\text { or lower }\end{array}$ & Diploma & Bachelor & $\begin{array}{l}\text { Master or } \\
\text { higher }\end{array}$ & \\
\hline Statement 13 & 3.98 & 4.283 & 4.026 & 4.093 & 0.027 \\
\hline Plastics & 1.389 & 1.38 & 1.335 & 1.685 & 0.022 \\
\hline
\end{tabular}

Table 9: Significant education level effects on output variables.

\begin{tabular}{|l|l|l|l|l|}
\hline \multirow{2}{*}{ Question } & \multicolumn{2}{|l|}{ Sean } & Married & Divorced \\
\cline { 2 - 4 } & Single & 4.171 & 3.2 & 0.022 \\
\hline Statement 6 & 4.227 & & \\
\hline
\end{tabular}


Page 7 of 8

\begin{tabular}{|l|l|l|l|l|}
\hline Statement 7 & 4.18 & 4.249 & 2.8 & 0 \\
\hline Statement 8 & 4.129 & 4.387 & 4 & 0 \\
\hline Statement 10 & 2.258 & 2.114 & 3.2 & 0.037 \\
\hline Statement 11 & 4.067 & 4.284 & 3.8 & 0 \\
\hline Statement 12 & 3.897 & 4.005 & 3.2 & 1 \\
\hline Aluminum & 1.206 & 1.09 & 1 & 0.039 \\
\hline Metals & 1.268 & 1.127 & 2.6 & 0.009 \\
\hline Paper recycling & 1.923 & 1.956 & 0.009 \\
\hline
\end{tabular}

Table 10: Significant Marital status effects on output variables.

\section{Discussion}

Results of the current study suggest that only a small percentage of people recycle domestic waste. This happens despite reporting being aware of the deterioration in environmental quality and that recycling preserves resources and protects the environment.

For any recycling program to be effective, positive perceptions of consumers (i.e., the general public) towards recycling should be translated to a positive recycling behaviour. However, results of the current study give a different picture. These results confirm that there is a disconnection between the attitude towards recycling and the actual behaviour of consumers in UAE. Participants to this study in general have a positive attitude towards recycling but, at the same time, the majority of them reported that they do not recycle. The positive perception and attitudes towards recycling among respondents is not translated to high level of participation in recycling.

This disconnection between attitude and behaviour might be due to some obstacles. One of those obstacles was investigated in the question "What would encourage your participation in recycling?" It is clear from the responses that long distance to recycling bins and lack of enough recycling bins is playing a negative role in respondents recycling habits. Many respondents confirmed their willingness to recycle as long as they have better accessibility and shorter distances to recycling bins.

Responses to the distributed questionnaire clearly show that the internet is the prime source of information on recycling in the country. This result is somehow anticipated given the fact that almost all people in the UAE have access to the internet. Nevertheless, other means, like radio/TV channels, posters, newspaper articles and school/university education should not be neglected as they still play an important role in spreading the message of recycling.

An interesting outcome of the current study is the high recycling rate of clothes as compared to all other recyclable items. This result may be attributed to the fact that many charity organizations put cloth recycling bins in shopping centers and public places. This encourages many people to donate their used clothes to charities instead of throwing them away. Then, these charities usually clean and repair the clothes and distribute them to the needy. This result indicates that any recycling program has the potential to succeed in the country if planned and executed properly in terms of both publicity and accessibility.
Results also show that there is public support for regulating recycling and introducing laws that would govern the recycling process. Currently there are no laws in UAE that govern recycling and the process is left to individual users and operators. Introducing such laws is essential to enhance the practice of recycling and govern it.

\section{Conclusions}

The rapid increase in waste production is a major environmental problem affecting environmental quality and the quality of life of people. Recycling is considered to be one of the solutions to this problem. However, there is a lack of published research studies that assessed domestic waste recycling attitude and practices among people in many developing countries including UAE. The aim of the current study was to investigate this issue though randomly distributing a structured and specially tailored questionnaire to 989 participants.

It was found that there is a gap between consumers attitude toward recycling and their actual behaviour and practices. Results indicate that some of the obstacles to people's participation in recycling is not finding enough recycling bins and the long distance to those bins. Results of the current study also indicate that the message of recycling is not reaching some sections of the society.

In order to create a culture for sustainability and a society that considers recycling to be one of its daily practices, three aspects are essential: education, publicity and promotion. These three aspects are essential for any recycling scheme to succeed [19]. Results of the current study show that there is a lack of awareness on domestic waste recycling among large sections of the UAE society. This lack of awareness needs to be addressed when trying to improve domestic waste recycling behaviour and practices of consumers through wellplanned and executed continuous public awareness campaigns. This is a big challenge in countries like UAE given the diversity of nationalities that live in UAE and the languages spoken. Therefore, government and non-governmental agencies are recommended to intensify their recycling awareness campaigns taking into consideration this diversity in languages spoken.

One of the ways governments can pursue to increase domestic waste recycling rates is to introduce mandatory waste collection laws. Such laws set recycling targets for cities to aim for. This is usually done in setting a certain percentage of a material to be diverted from the general waste stream to be recycled by a target date. The city is then responsible for working to meet this target [4]. This can only be 
achieved after improving accessibility to recycling bins for the general public by increasing their numbers and changing their locations to suit more potential users.

Another way governments can pursue to increase domestic recycling rates is to legislate to impose a surcharge on the price of items when sold in recyclable bottles and containers. This legislation usually involves offering a refund upon returning these items (typically glass, plastic or metal) to a collection point. Such programs have been reported to be very successful in improving recycling rate of those items for up to 80 percent [4].

It is clear from the literature review that there is a scarcity of research in areas related to consumers' attitude and behaviour on recycling in developing countries including UAE. More research is recommended in this area. Also, it is recommended that municipalities should collect and publish statistics on recycling volumes. Without such statistics, any progress in recycling effort and practices cannot be detected.

\section{Limitations of Study}

This current study concentrates on domestic waste recycling in UAE. More research is needed on consumers' attitude and behaviour towards recycling of other types of waste. Also, results of the current study are based on surveying a limited number of people. Thus, these results should be taken cautiously keeping in mind that no previous published articles exist in this area to do any comparisons.

\section{References}

1. Abdul Latif S, Omar MS (2012) Recycling Behaviour in Tioman Island: A Case Study. Proc Soc and Behav Sci 36: 707-715.

2. Nnorom IC, Ohakwe J, Osibanjo O (2009) Survey of willingness of residents to participate in electronic waste recycling in Nigeria-A case study of mobile phone recycling. J Cle Prod 17: 1629-1637.

3. Gilpin A (2000) Dictionary of Environmental Law. Edward Elgar Publishing Limited, London, UK.

4. Banerjee R (2015) Importance of Recycling. IJIREEICE 3: 2321-5526.

5. Poon CS, Ann TW, Ng LH (2001) On-site sorting of construction and demolition waste in Hong Kong. Resour Conserv and Recycl 32: 157-172.
6. Zhuang Y, Wu SW, Wang YL, Wu WX, Chen YX (2008) Source separation of household waste: A case study in China. Waste Manag 28: 2022-30.

7. Saphores JM, Nixon H (2014) How effective are current household recycling policies? Results from a national survey of U.S. households. Resour Conserv and Recycl 92: 1-10.

8. Zain S, Basri NA, Basri H, Zakaria N, Elfithri R, et al. (2012) Focusing on Recycling Practice to Promote Sustainable Behaviour. Proc Soc Behav Sci 60: 546-555.

9. McDonald S, Ball R (1997) Public participation in plastics recycling schemes. Conser Recycl 22: 123-141.

10. Huang P, Zhang X, Deng X (2006) Survey and analysis of public environmental awareness and performance in Ningbo, China: a case study on household electrical and electronic equipment. J Clean Prod 14: 1635-1643.

11. Lakhan C (2015) Differences in self-reported recycling behaviour of first and second generation South Asians in Ontario. Resour, Conser and Recycl 97: 31-43.

12. Foster S, Hirata R, Games D, D’Elia M, Paris M (2007) Groundwater Quality Protection: a guide for water utilities, municipal authorities, and environment agencies. The World Bank, Washington, D.C.

13. Mor S, Ravindra K, Dahiya RP, Chandra A (2006) Leachate Characterization and assessment of groundwater pollution near municipal solid waste landfill site. Envir Monit Asses 118: 435-456.

14. Biswas AK, Kumar S, Babu SS, Bhattacharyya JK, Chakrabat T (2010) Studies on environmental quality in and around municipal solid waste dumpsite. Resour, Conser and Recycl 55: 129-134.

15. Berger IE (1997) The demographics of recycling and the structure of environmental behaviour. Envir and Behav 29: 515-31.

16. Tilikidou I, Delistavrou A (2001) Utilization of Selected Demographics and Psychographics in Recycling Behaviour Understanding: A Focus on Materialism. Green Manag Int J 34: 75-93.

17. Kurz T, Linden M, Sheehy M (2007) Attitudinal and community influences on participation in new curbside recycling initiatives in Northern Ireland. Environ Behav 39: 367-391.

18. Dwivedy R, Mittal RK (2015) Willingness of residents to participate in ewaste recycling in India. Enviro Develop 6: 48-68.

19. National Bureau of Statistics (2014) UAE in numbers 2013, Abu DhabiUnited Arab Emirates. $s$

20. Evison T, Read DA (2001) Local Authority recycling and waste awareness. Resour Conser and Recycl 32: 275-291. 